\title{
AÇÕES AFIRMATIVAS: POLÊMICAS E POSSIBILIDADES SOBRE IGUALDADE RACIAL E O PAPEL DO ESTADO
}

\author{
SALES AUGUSTO DOS SANTOS \\ Universidade de Brasília \\ ELIANE CAVALLEIRO \\ Universidade de Brasília \\ MARIA INÊS DA SILVA BARBOSA
}

Secretaria Especial de Políticas de Promoção da Igualdade Racial

\section{MATILDE RIBEIRO}

Núcleo de Estudos e Pesquisas sobre Movimentos Sociais - Nemos (PUC/SP)

Resumo: O artigo analisa a importância do papel do Estado para a implementação das políticas públicas de ação afirmativa, especialmente para estudantes negros ingressarem no ensino superior público. Argumenta-se que a ação afirmativa é uma das alternativas para reduzir ou minimizar a desigualdade de inserção entre estudantes negros e brancos de escolas públicas e/ou particulares no ensino superior, especialmente por meio de uma de suas técnicas de implementação: o sistema de cotas. Embora haja vários argumentos contra o sistema de cotas, os autores se concentraram em debater ou contra-argumentar apenas um: o de que o sistema de cotas poderá gerar conflitos raciais no Brasil.

Palavras-chave: políticas públicas; ações afirmativas; sistema de cotas; ensino superior; conflitos raciais.

\section{Introdução}

É de conhecimento de todos que o Brasil é um país formado por diferentes povos (indígenas, africanos, europeus, asiáticos, entre outros) e que a interação social entre eles

Copyright $\odot 2008$ by Revista Estudos Feministas. 
foi desigual desde o início da colonização portuguesa. Alguns desses povos, especialmente os brancos de origem européia, lograram vários privilégios em relação aos demais povos que formaram a nação brasileira. Em decorrência disso, até hoje, convivemos com grandes desigualdades pautadas por diferenças de pertencimento de classe social, de grupo racial e de sexo/gênero. Assim, no Brasil, ricos e pobres, mulheres e homens, negros, indígenas, brancos, amarelos, entre outros, têm possibilidades e maneiras muito distintas e desiguais para a obtenção de bônus e de pagamento dos ônus sociais.

As diferenciações e as desigualdades citadas não são características exclusivas de nosso país. E há soluções, por meio de um conjunto de medidas, para superar todas as injustiças contra a maioria do povo brasileiro. Para tentar amenizar as desigualdades supracitadas e possibilitar que todos os grupos sociais brasileiros desenvolvam o seu potencial humano (intelectual, cultural, econômico, educacional etc.), não temos dúvida de que a educação formal e de qualidade nos diferentes níveis de ensino deva ser direito formal e substantivo de todos os grupos sociorraciais.

Porém, lamentavelmente as desigualdades na esfera da educação são gritantes, por exemplo, em geral os homens brancos nascidos nas regiões Sul ou Sudeste são mais escolarizados e tendem a adquirir maior destaque social em nosso país. Na contramão desse processo estão as mulheres negras, especialmente as nascidas nas regiões Norte e Nordeste e com baixa escolaridade.

Apesar desses traços nas nossas relações sociais, a expansão contemporânea do ensino público tem possibilitado que negros e mulheres consigam concluir a educação básica. Finda essa fase, esse grupo de pessoas, antes alijados do processo de escolarização, também começa a demandar inserção em todos os cursos superiores. Para as mulheres brancas com melhores condições econômicas, a realização dessa demanda vem ocorrendo faz algum tempo. Boa parte delas, após concluir o ensino médio, tem tido acesso ao nível superior público, embora a grande maioria ainda esteja inserida em cursos caracterizados como de menor valor social, como, por exemplo, psicologia, pedagogia, nutrição, enfermagem. Mesmo nesses cursos não valorizados adequadamente no mercado de trabalho, e até mesmo no meio universitário, o número de alunas e alunos negros é ainda ínfimo.

Não temos dúvidas de que esse quadro é, ainda, reflexo do processo de formação desigual e injusta do País, ou seja, a nossa formação nacional fundada sob os valores da escravidão e do racismo levou a sociedade brasileira a discriminar e/ou excluir racialmente a população negra, o que, conseqüentemente, concentrou-a nos níveis socioeconômicos mais baixos.

Nas últimas décadas nosso país passou a ter expansão da educação básica, e temos uma boa parte dos nossos estudantes concluindo-a. Todavia, considerando as péssimas condições de vida da maioria absoluta dos nossos estudantes, a (falta de) qualidade do ensino oferecido a eles, bem como o racismo, o sexismo, a homofobia, entre outras discriminações contra eles em nossas escolas, a competição por vagas em nossas melhores universidades, entre os estudantes de escolas públicas e os alunos mais ricos que estudam em escolas particulares, é muito desigual; mesmo assim, hoje, muitos de nossos estudantes de escolas públicas têm conseguido concluir o ensino médio.

Quando da necessária inserção no curso superior, lamentavelmente não há vagas disponíveis para todos e em todas as carreiras. Uma alternativa para reduzir ou minimizar a desigualdade de inserção entre estudantes negros e brancos e/ou de escolas públicas e particulares no ensino superior foi a demanda e/ou proposta dos movimentos negros por um tipo de implementação técnica de política de ação afirmativa, o sistema de cotas. 
Várias críticas surgiram contra essa alternativa que consideramos viável, necessária e justa. E a inserção diferenciada no ensino superior público brasileiro de estudantes negros e/ou pobres é importante não somente para amenizar a enorme desigualdade quando se compara a pequena inserção desses alunos com a dos alunos brancos e/ou ricos, como essa inserção diferenciada possibilita a convivência entre estudantes de classes sociais e grupos raciais diferentes; contribui para a revisão e a reprovação de preconceitos raciais, de classe e de atitudes discriminatórias; possibilita a formação de profissionais negros ou de origem social pobre gerando novas referências para a sociedade brasileira e novas visões sobre a sociedade brasileira; democratiza (mesmo que minimamente) bens culturais produzidos na sociedade; e, entre outras vantagens, melhora a qualidade de vida dos grupos historicamente vulneráveis, podendo inclusive diminuir a desigualdade sociorracial em nosso país. E não temos dúvida de que ela também ajudará a diminuir as desigualdades abismais que existem entre todos os demais grupos sociais e as mulheres negras, que são as mais discriminadas na sociedade brasileira, por serem negras e mulheres.

Como afirmamos, há vários argumentos contra o sistema de cotas, mas vamos nos concentrar em debater apenas um, o de que o sistema de cotas poderá gerar conflitos raciais no Brasil. Além disso, comentaremos rapidamente a importância do papel do Estado para a implementação dessas políticas públicas.

\section{Ações afirmativas e o papel do Estado brasileiro}

A não aceitação e a indignação contra as discriminações racial e de gênero, que foram impostas historicamente aos negros e às mulheres, são pontos cruciais para nos direcionarmos às políticas de ações afirmativas, buscando construir um novo conjunto de direitos bem como a restauração das capacidades humanas desses grupos vulnerabilizados pelas discriminações.

Kimberlé Crenshaw, ao refletir sobre as questões de gênero e raça, ${ }^{1}$ aponta a importância da ampliação do enfrentamento do abuso dos direitos relativos às mulheres, no campo dos direitos humanos. No entanto, apresenta também uma reflexão partindo da existência da interseccionalidade entre gênero e raça, assinalando a coexistência entre ambas. Segundo a autora, discriminação racial,

é freqüentemente marcada pelo gênero, pois as mulheres podem às vezes vivenciar discriminações e outros abusos dos direitos humanos de uma maneira diferente dos homens. O imperativo de incorporação do gênero põe em destaque as formas pelas quais homens e mulheres são diferentemente afetados pela discriminação racial e por outras intolerâncias correlatas. ${ }^{2}$

Por caminhos e áreas diferenciados pesquisadores e pesquisadoras brasileiros Eliane Cavalleiro, ${ }^{3}$ Flávia Piovesan, ${ }^{4}$ Maria Inês da Silva Barbosa, ${ }^{5}$ Matilde Ribeiro, ${ }^{6}$ Sales Augusto dos Santos ${ }^{7}$ - e estrangeiros - Kimberlé Crenshaw ${ }^{8}$ e Edward Telles, ${ }^{9}$ entre outros -

\footnotetext{
${ }^{1}$ Gênero e raça são construções sociais que resultam invariavelmente em transformação de diferenças em desigualdades. Vale reafirmar que raça não é uma categoria natural ou biológica, enquanto sexo, sim, traduz o ser homem ou mulher com suas diferenças biológicas.

${ }^{2}$ Kimberlé CRENSHAW, 2002, p. 173.

${ }^{3}$ Eliane CAVALLEIRO, 2003, 1998.

${ }^{4}$ Flávia PIOVESAN, 2007.

${ }^{5}$ Maria Inês da Silva BARBOSA, 1998.

${ }^{6}$ Matilde RIBEIRO, 1995, 1999, 2006, 2008.

7 Sales Augusto dos SANTOS, 2006, 2007.

8 CRENSHAW, 2002.

${ }^{9}$ Edward Eric TELLES, 2003.
} 
vêm realizando estudos demarcando que, no Brasil, as diferenças têm gerado desigualdades e, por conseqüência, disparidades no tratamento das políticas públicas ora entre brancos e negros, ora entre homens e mulheres e ora entre as condições de gênero e raça. É apontada nesses estudos a necessidade de consideração das diferenças como elementos "saudáveis" que devem ser absorvidos de forma positiva nas políticas públicas e, também, na aplicação das políticas de ações afirmativas.

Essas perspectivas nos advertem da necessidade de políticas públicas, em especial ações afirmativas visando à inclusão de negros e mulheres na sociedade brasileira, de tal forma que esses grupos possam ter pleno desenvolvimento social, político, cultural, educacional e econômico.

O que vêm a ser políticas de ações afirmativas? Há vários conceitos sobre esse termo, destacamos a elaboração de Joaquim B. Barbosa Gomes:

as ações afirmativas consistem em políticas públicas (e também privadas) voltadas à concretização do princípio constitucional da igualdade material e à neutralização dos efeitos da discriminação racial, de gênero, de idade, de origem nacional e de compleição física. Impostas ou sugeridas pelo Estado, por seus entes vinculados e até mesmo por entidades puramente privadas, elas visam a combater não somente as manifestações flagrantes de discriminação, mas também a discriminação de fundo cultural, estrutural, enraizada na sociedade. De cunho pedagógico e não raramente impregnadas de um caráter de exemplaridade, têm como meta, também, o engendramento de transformações culturais e sociais relevantes, inculcando nos atores sociais a utilidade e a necessidade da observância dos princípios do pluralismo e da diversidade nas mais diversas esferas do convívio humano. Constituem, por assim dizer, a mais eloqüente manifestação da moderna idéia de Estado promovente, atuante, eis que de sua concepção, implantação e delimitação jurídica participam todos os órgãos estatais essenciais, aí incluindo-se o Poder Judiciário, que ora se apresenta no seu tradicional papel de guardião da integridade do sistema jurídico como um todo, ora como instituição formuladora de políticas tendentes a corrigir as distorções provocadas pela discriminação. ${ }^{10}$

Ainda, segundo Mary Castro ${ }^{11}$ e Marlise Almeida, ${ }^{12}$ as ações afirmativas, como parte dos debates contemporâneos, devem, sem dúvida, pautar-se pela lógica complexa e complementar entre demandas de redistribuição e de reconhecimento pertinentes às atuais reivindicações políticas. Portanto, o Estado deve se posicionar por meio de ações concretas, ou seja, ser promovente e ir além de declaração de boas intenções e de programas pontuais para este ou aquele grupo social. Como exemplo, e ao contrário do pensamento (talvez mais sentimento que pensamento) da maioria dos intelectuais brancos das ciências sociais que são contra as políticas de ações afirmativas para estudantes negros, devemos explicitar que o Estado deve apoiar e incentivar o sistema de cotas no ensino superior, uma vez que, sob o ponto de vista dos direitos humanos, esse sistema visa à igualdade de oportunidades e de tratamento, bem como repor direitos - neste caso o direito fundamental à educação superior de qualidade - que foram e são sistemática e historicamente violados e usurpados da população negra diante da discriminação racial.

Em âmbito nacional, é importante destacar que as políticas públicas de cunho democrático e de inclusão social, como as de ação afirmativa, pautam-se pelas leis nacionais, tendo como principal referência a Constituição Federal Brasileira, considerada

\footnotetext{
10 Joaquim B. Barbosa GOMES, 2001, p. 6-7.

1 Mary Garcia CASTRO, 2004.

${ }^{12}$ Marlise M. M. ALMEIDA, 2007.
} 
uma "Constituição Cidadã". Esse argumento é ratificado juridicamente por Marco Aurélio de Mello:

urge a compreensão de que não se pode falar em Constituição sem levar em conta a igualdade, sem assumir o dever cívico de buscar o tratamento igualitário, de modo a saldar dívidas históricas para com as impropriamente chamadas minorias, ônus que é de toda a sociedade. [...] É preciso buscar a ação afirmativa. A neutralidade estatal mostrou-se um fracasso. Há de se fomentar o acesso à educação; urge um programa voltado aos menos favorecidos, a abranger horário integral, de modo a tirar-se meninos e meninas da rua, dando-se-lhes condições que os levem a ombrear com as demais crianças. E o Poder Público, desde já, independentemente de qualquer diploma legal, deve dar à prestação de serviços por terceiros uma outra conotação, estabelecendo, em editais, quotas que visem a contemplar os que têm sido discriminados. [...] Deve-se reafirmar: toda e qualquer lei que tenha por objetivo a concretude da Constituição não pode ser acusada de inconstitucional. Entendimento divergente resulta em subestimar ditames maiores da Carta da República, que agasalha amostragem de ação afirmativa, por exemplo, no artigo $7^{\circ}$, inciso $\mathrm{XX}$, ao cogitar da proteção de mercado quanto à mulher e da introdução de incentivos; no artigo $37^{\circ}$, inciso III, ao versar sobre a reserva de vagas - e, portanto, a existência de quotas -, nos concursos públicos, para os deficientes; nos artigos $170^{\circ}$ e $227^{\circ}$, ao emprestar tratamento preferencial às empresas de pequeno porte, bem assim à criança e ao adolescente.

Com isso, é enfatizado não somente a constitucionalidade da política, como demonstrado, a Constituição Federal de 1988 incorpora amostragem de ação afirmativa.

Toda essa construção nacional, embora ainda muito frágil e complexa, articula-se com a Declaração Universal dos Direitos Humanos, adotada na França/Paris, em 10 de dezembro de 1948, com a Convenção Internacional sobre a Eliminação de todas as Formas de Discriminação Racial - ICERD, em 1965, e com a Convenção sobre a Eliminação de todas as Formas de Discriminação Contra a Mulher-CEDAW, em 1979. São esses importantes instrumentos mundiais para a garantia de direitos e melhoria de condições de vida de todos os cidadãos e cidadãs, sem distinção.

Esses e tantos outros instrumentos, também, foram base para a realização do Ciclo das Conferências Mundiais, promovido pela Organização das Nações Unidas " ONU, nos anos 1990. Todas essas conferências ${ }^{14}$ direta ou indiretamente estimularam debates e proporcionaram formulações nas esferas da vida social, econômica, política e cultural, possibilitando o entendimento da necessidade de defesa de outras políticas públicas, como as de ações afirmativas, bem como o entendimento da necessidade do respeito à diversidade.

Flávia Piovesan argumenta que a Conferência de Viena ${ }^{15}$ trouxe um impulso substantivo e animador no campo legal e de políticas públicas, tendo por base a formulação sobre universalidade e indivisibilidade dos direitos humanos, partindo da interdependência

\footnotetext{
${ }^{13}$ Marco Aurélio de MELLO, 2001, p. 5.

${ }^{14}$ Neste artigo daremos destaque à Conferência Mundial sobre os Direitos Humanos (Áustria - Viena, 1993), Conferência Mundial sobre a Mulher (China - Beijing, 1995) e III Conferência Mundial contra o Racismo, a Discriminação Racial, a Xenofobia e as Formas Conexas de Intolerância (África do Sul - Durban, 2001), mas é importante considerar também a realização da Conferência Mundial sobre Meio Ambiente e Desenvolvimento (Brasil - Rio de Janeiro, 1992), da Conferência Internacional sobre População e Desenvolvimento (Egito Cairo, 1994), da Cúpula Mundial de Desenvolvimento Social (Dinamarca - Copenhague, 1995), da Conferência Mundial sobre os Assentamentos Humanos - Habitat II (Turquia - Istambul, 1996) e da Cúpula Mundial sobre Alimentação (Itália - Roma, 1996).

15 ONU, 1993.
} 
entre as áreas civis, políticas, econômicas, sociais e culturais. Segundo a pesquisadora, mesmo considerando os avanços, deve-se acrescentar aos resultados da Conferência de Viena o valor e o princípio da "diversidade", pois a violação dos direitos humanos alcança prioritariamente os grupos vulneráveis como, por exemplo,

as mulheres, as populações afrodescendentes e os povos indígenas - daí os fenômenos da 'feminilização' e 'etnização' da pobreza [...]. A efetiva proteção dos direitos humanos demanda não apenas políticas universalistas, mas específicas, endereçadas a grupos socialmente vulneráveis, enquanto vítimas preferenciais da exclusão. ${ }^{16}$

Já a Declaração de Viena e o Programa de Ação de Beijing ${ }^{17}$ diagnosticam e apontam medidas para alteração das condições de vida, reafirmando compromissos em prol dos direitos humanos das mulheres. As feministas brasileiras, ao analisarem o processo dessa conferência, alegam que o debate que antecedeu a aprovação dos documentos finais, o uso do termo "raça e etnia", gerou longa e dura controvérsia. Porém, como um avanço, os documentos finais trazem menções explícitas desses termos, partindo da necessidade de superação de injustiça social que abate sobre a população não branca, discriminada pelo racismo.

A III Conferência Mundial contra o Racismo, a Discriminação Racial, a Xenofobia e as Formas Conexas de Intolerância - realizada no período de 31 de agosto a 8 de setembro de 2001, em Durban, na África do Sul - teve como slogan: "Unidos para combater o racismo: Igualdade, Justiça e Dignidade" e foi conectada à agenda de "2001 - Ano Internacional de Mobilização contra o Racismo, a Discriminação Racial, a Xenofobia a as Formas Conexas de Intolerância".

A "Declaração e Programa de Ação de Durban"18 estabelecem com maior ênfase quem são as vítimas do racismo, da discriminação racial, da xenofobia e de outras formas de intolerância, destacando em sua ampla agenda as múltiplas formas de discriminação que podem afetar sobremaneira as mulheres (em particular as mulheres negras e indígenas) e impedir que elas desfrutem ampla e dignamente seus direitos civis, políticos, econômicos, sociais e culturais.

Foi considerado que o colonialismo tem levado ao racismo e afetado mais diretamente os africanos e os afrodescendentes, as pessoas de origem asiática e os povos indígenas. A partir daí, foi anunciado que a escravidão e a servidão dos descendentes de africanos, caribenhos, povos indígenas, como também de outros povos discriminados, cujas seqüelas ainda são vigentes, constituíram crimes de lesa humanidade. Por isso, foi reafirmada a visão sobre o direito dos povos vitimados à reparação.

Nesse sentido, o Programa de Ação de Durban parte da necessidade de aplicar os objetivos, destacando-se os artigos 99 e 100:

- Reconhece que o combate ao racismo, discriminação racial, xenofobia e intolerância
correlata é responsabilidade primordial dos Estados. Portanto, incentiva os Estados a
desenvolverem e elaborarem planos de ação nacionais para promoverem a
diversidade, igualdade, eqüidade, justiça social, igualdade de oportunidades e
participação para todos. Através, dentre outras coisas, de ações e de estratégias
afirmativas ou positivas; estes planos devem visar a criação de condições
necessárias para a participação efetiva de todos nas tomadas de decisão

16 PIOVESAN, 2007, p. 27.

17 ONU, 1995.

$18 \mathrm{ONU}, 2002$. 
e o exercício dos direitos civis, culturais, econômicos, políticos e sociais em todas as esferas da vida com base na não-discriminação.

- Insta os Estados a estabelecerem, com base em informações estatísticas, programas nacionais, inclusive programas de ações afirmativas ou medidas de ação positivas, para promoverem o acesso de grupos de indivíduos que são ou podem vir a ser vítimas de discriminação racial nos serviços básicos, incluindo, educação fundamental, atenção primária à saúde e moradia adequada.

Sueli Carneiro ${ }^{20}$ a partir do instigante artigo "A batalha de Durban" resgata que os documentos aprovados em Durban instam os Estados a adotar posturas de eliminação da desigualdade racial e de gênero. Portanto, chama a atenção que o papel dos governos ou do Estado para a implementação e o sucesso das políticas públicas de ação afirmativa é não só necessário mas também indispensável.

No Brasil, antes mesmo do Ciclo das Conferências Mundiais, a partir da segunda metade dos anos 1980, vêm sendo realizadas ações, mesmo que insuficientes, nas três instâncias do governo (Federal, Estadual e Municipal), voltadas às mulheres e aos negros e mais recentemente aos jovens e aos homossexuais. Isso se dá em resposta às pressões dos movimentos sociais, dos quais destacamos os movimentos negros e feministas. ${ }^{21}$ Segundo Matilde Ribeiro, ${ }^{22}$ no interior desses e nas últimas décadas com organização autônoma, é, ainda, importante destacar as organizações de mulheres negras que enfatizam o valor da diversidade e o empoderamento dessas como agentes políticas.

Primeiramente, foram criados os conselhos das mulheres e de negros, depois as delegacias de defesa das mulheres, os SOS racismo, bem como delegacias contra discriminação racial. Em seguida, foram criados órgãos articuladores e/ou executores de promoção da igualdade racial e/ou de gênero, como secretarias, coordenadorias, assessorias e afins.

Atualmente, tem-se buscado desenvolver ações afirmativas a partir da intersetorialidade das políticas públicas nos diversos órgãos de governo sob orientação e coordenação de alguns órgãos, como a Secretaria Especial de Políticas para as Mulheres SPM, a Secretaria Especial de Políticas de Promoção da Igualdade Racial - Seppir, a Secretaria Especial dos Direitos Humanos - SEDH e também a Secretaria Nacional de Juventude - SNJ. Vale ressaltar que tem sido extremamente salutar o processo de debates e de consultas por meio dos canais de participação, como conselhos de políticas públicas e de direitos, ouvidorias, conferências, consultas públicas, entre outros.

Tudo isso, associado principalmente às pressões dos movimentos negros por igualdade racial, tem possibilitado a discussão e a necessidade de políticas de ações afirmativas para grupos sociais que historicamente têm sido discriminados na sociedade brasileira. ${ }^{23}$ Dessa maneira, tem sido desenvolvido um "casamento" necessário e imprescindível entre políticas universalistas e políticas públicas específicas, como as de ação afirmativa.

\footnotetext{
19 PROGRAMA... apud C. A. MOURA e Jônatas Nunes BARRETO, 2002, p. 131, grifo nosso.

${ }^{20}$ Sueli CARNEIRO, 2002.

${ }^{21}$ Aqui utilizaremos o termo "movimentos negros e feministas", conforme decisão coletiva entre os quatro autores. Embora em outros textos deste dossiê Matilde Ribeiro utilize o termo "MOVIMENTO NEGRO e feminista" (no singular), sendo essa a sua posição pessoal.

22 RIBEIRO, 1995, 2006.

${ }^{23}$ A Seppir foi criada em 21 de março de 2003 após intensas negociações entre o Governo Federal, depois da posse do Presidente Luiz Inácio LULA da Silva, e representações de entidades nacionais do MOVIMENTO NEGRO.
} 
Tais políticas, pautadas pelas demandas dos movimentos negro e feminista, intensificaram significativas mudanças na sociedade brasileira, em que o racismo e o sexismo estão sendo questionados profundamente, embora haja fortes forças conservadoras, lideradas inclusive por renomados cientistas sociais, lutando pela manutenção do antigo status quo.

As leis, espelhando as lutas sociais, têm construído um caminho inverso a essas tais forças conservadoras. Em 9 de janeiro de 2003, foi alterada a lei que estabelece as Diretrizes e Bases da Educação Nacional - LDB 9394/96, incluindo no currículo do ensino fundamental e médio da rede de ensino público e privado o ensino de história e cultura afro-brasileira Lei n. 10.639; em 11 de março de 2008, a LDB foi alterada pela Lei n. 11.645/08, tornando também obrigatório o ensino da história e cultura dos povos indígenas.

Do ponto de vista da educação em nível superior no Brasil, hoje, dezembro de 2008, existem 84 instituições de ensino público que nos últimos oito anos adotaram algum tipo de ação afirmativa de ingresso, incluindo o sistema de cotas. ${ }^{24}$ Tem-se a avaliação de desempenho próximo, similar ou até melhor dos alunos cotistas em relação aos não cotistas.

Segundo o lpea, no biênio 2005-2006, cotistas obtiveram maior média de rendimento em 31 dos 55 cursos (Unicamp) e coeficiente de rendimento (CR) igual ou superior aos de não cotistas em 11 dos 16 cursos (UFBA). Na UnB, não cotistas tiveram maior índice de aprovação $(92,98 \%$ contra $88,90 \%)$ e maior média geral do curso $(3,79 \%$ contra $3,57 \%)$, porém trancaram $1,76 \%$ das matérias, contra $1,73 \%$ dos cotistas. Por outro lado, dados do Censo Educacional de 2005 do MEC mostram ainda que instituições públicas realizam, em média, 331 mil matrículas anualmente. Apenas 2,37\% (cerca de 7.850) delas são destinadas a estudantes negros. ${ }^{25}$

Por parte do Legislativo, temos em 20 de novembro de 2008 a aprovação na Câmara Federal do PL $73 / 99$, que reserva $50 \%$ das vagas das universidades públicas a alunos que cursaram integralmente o ensino médio em escolas públicas, respeitando o percentual de negros e indígenas em cada Unidade da Federação. O projeto segue para aprovação no Senado Federal.

Essas medidas, sem dúvida, dão concretude às perspectivas anunciadas, ainda em 2002, por Luciana Jacoud e Nathalie Beghin, que ao tratarem das ações afirmativas admitem que

o reconhecimento de que a igualdade formal não garante aos que são socialmente desfavorecidos o acesso às mesmas oportunidades que têm aqueles que são socialmente privilegiados promoveu um esforço de ampliação não apenas do conteúdo jurídico e moral da idéia de igualdade, mas das próprias possibilidades jurídicas de concretizá-la. ${ }^{26}$

Com isso, as políticas de ação afirmativa partem de uma crítica ao princípio da igualdade formal diante da lei e reforçam a perspectiva de igualdade de oportunidade. ${ }^{27}$ Segundo Marcelo Paixão:

As políticas de ação afirmativas estão fundamentadas em um princípio ético que, buscando a superação das desigualdades (sociais, raciais, éticas, de gênero, de outras

\footnotetext{
${ }^{24}$ Os dados do Programa Políticas da Cor - PPCOR/UERJ-2008 contém na lista 78 instituições de ensino com algum tipo de ação afirmativa. Outros dados (seis novas universidades) foram agregados pelos autores.

25 IPEA, 2008.

${ }^{26}$ Luciana JACOUD e Nathalie BEGHIN, 2002, p. 45-46.

${ }^{27}$ Esta é uma formulação presente no "Programa para Superação do Racismo e da Desigualdade Racial" Marcha Zumbi dos Palmares contra o Racismo, pela Cidadania e a Vida.
} 
minorias), defende $a_{28}$ hipótese da concessão de tratamento desigual a pessoas socialmente desiguais.

Dessa maneira, compreende-se que, quando aplicadas, as ações afirmativas restituem a igualdade de oportunidades entre os diferentes grupos raciais, promovendo um tratamento diferenciado e preferencial àqueles historicamente marginalizados.

\section{Cientistas sociais: pesquisa acadêmico-científica ou futurologia?}

Como dito, há fortes forças conservadoras contra as políticas de ações afirmativas para estudantes negros. E há também entre alguns cientistas sociais contrários às cotas para estudantes negros uma desconsideração ou negação do conhecimento acadêmico já produzido a respeito de ações afirmativas. Tal desconsideração sobre o assunto põe no mínimo em suspeita as críticas às políticas afirmativas, pois essas não nascem de estudos sistematizados ou da revisão dos referenciais teóricos sobre ações afirmativas para produzir novos conhecimentos ou mesmo confirmar ou reformular conhecimentos anteriores e, conseqüentemente, criticar o sistema de cotas.

Por exemplo, os antropólogos e professores titulares do Instituto de Filosofia e Ciências Sociais - IFCS, da Universidade Federal do Rio de Janeiro "UFRJ, Peter Fry ${ }^{29}$ e Yvonne Maggie, ${ }^{30}$ ou ainda Fry e Maggie ${ }^{31}$ e Maggie e Fry, ${ }^{32}$ dois dos mais contundentes críticos das políticas de cotas nas universidades públicas brasileiras, ao escreverem artigos e até mesmo livros sobre a questão racial e a implementação de ações afirmativas para negros na educação superior brasileira, citam várias vezes no mesmo artigo ou livro a expressão "ação afirmativa" e jamais entram na discussão teórica sobre esse tema, nem sequer apresentam um conceito ou uma definição explícita, conforme se pode ver em Santos. ${ }^{33}$

Ao desconsiderarem esses procedimentos metodológicos sobre a produção do conhecimento acadêmico-científico, alguns cientistas sociais contrários às cotas para negros fazem, em geral, apenas previsões sem fundamento histórico para a sociedade; previsões que muito se aproximam de futurologia e muito se afastam da construção de conhecimento fundamentado em pesquisas e no rigor acadêmico.

Essa fórmula permite a divulgação de afirmações esvaziadas de concretude do tipo: "as cotas para negros nos vestibulares das universidades públicas vão racializar a sociedade brasileira", ou ainda "vai haver uma divisão racial do Brasil", ou "divisões perigosas", entre outras insustentáveis previsões catastróficas.

Cabem, desse modo, duas breves considerações. A primeira diz respeito aos autores que são contra as cotas para negros nos vestibulares e mesmo assim admitem que a sociedade brasileira discrimina racialmente os negros. ${ }^{34}$ Ora, existe sociedade que

\footnotetext{
${ }^{28}$ Marcelo PAIXÃO, 2006, p. 132.

${ }_{29}$ Peter FRY, 2000, 2002, 2003, 2005a, 2005b, 2005-2006.

30 Yvonne MAGGIE, 2001, 2004, 2005a, 2005b, 2005-2006, 2006.

${ }^{31}$ FRY e MAGGIE, 2004.

${ }^{32}$ MAGGIE e FRY, 2002, 2004.

33 SANTOS, 2007.

${ }^{34}$ Por exemplo, segundo Peter Fry, "†odos nós sabemos das grandes e pequenas discriminações e humilhações que os cariocas mais escuros e mais pobres vivem cotidianamente. Todos nós gostaríamos de ver as universidades públicas cada vez mais multicoloridas (as privadas já são). Também acredito que a maioria quer que o Brasil elimine o racismo de tal jeito que a discriminação racial e o medo dela deixem de ferir tanto. Mas a 'solução' das cotas vai aumentar os problemas, não diminuí-los" (2003).
} 
discrimina racialmente os negros e que não é racializada? Se uma sociedade é racista contra um determinado grupo social é porque ela racializa, ou seja, usa a raça para classificar e julgar previamente os seus cidadãos, alguns positivamente e outros negativamente, não levando em consideração somente o seu caráter para julgá-los. Portanto, não é à toa que os dados estatísticos oficiais (do Instituto Brasileiro de Geografia e Estatística - IBGE e do Instituto de Pesquisa Econômica Aplicada - Ipea) e não oficiais (do Departamento Intersindical de Estatística e Estudos Socioeconômicos - DIEESE) mostram uma desigualdade racial brutal entre negros e brancos no Brasil. ${ }^{35}$

A segunda consideração discute por que esses cientistas começam a trabalhar com cenários desanimadores sobre o futuro do Brasil no que diz respeito às relações raciais. O receio de um futuro violento passa a ser um dos argumentos desses autores contra as cotas, visto que eles descortinam, com a implantação das políticas de ação afirmativa para negros, cenários de conflito racial aberto no tempo que há de vir. Por exemplo, Maggie e Fry já compartilharam a escrita de artigos $^{36} \mathrm{em}$ que fazem previsões não otimistas sobre 0 futuro racial do Brasil após o processo de implementação das ações afirmativas para os negros. Segundo esses artigos, dentre outros, as cotas vão aumentar o "acirramento das tensões raciais existentes" e provocarão uma "cisão racial" no Brasil.

Tal previsão sem lastro sócio-histórico, ao que tudo indica, tende a ser mais uma das muitas que já foram feitas (e não se realizaram) na esfera das relações raciais, algumas vezes supondo: a) um melhoramento ou um acirramento das relações raciais brasileiras no futuro; e b) mudanças profundas na composição racial do Brasil pela extinção dos negros e dos indígenas, entre outras previsões.

E previsões sobre a composição racial brasileira e sobre as relações raciais no Brasil não deixaram de existir ao longo de todo o século XX, bem como também não se realizaram até a presente data. Por exemplo, em 1982, segundo o historiador Clóvis Moura, ${ }^{37}$ assessor do antigo Banco do Estado de São Paulo "Banespa, apresentou um trabalho no qual previa que a população negra brasileira chegaria a $60 \%$ do total de brasileiros no ano 2000 , podendo inclusive tomar o controle político do País e dominar os postos-chave. Nada disso aconteceu no ano 2000.

Durante o regime militar no Brasil, mais precisamente no final da década de 1960 , também houve medos e previsões de que poderia haver conflitos raciais manifestados pública e abertamente no Brasil do futuro, ou seja, do ano 2000. Nessa época, o jornalista Itamar de Freitas organizou uma equipe de pesquisadores e intelectuais (sociólogos, etnólogos, educadores, entre outros) para discutir como seria o Brasil no ano 2000 . O resultado desse trabalho prospectivo foi o livro Brasil ano 2000: o futuro sem fantasia, publicado pela editora Biblioteca do Exército Brasileiro, em 1969.

Apoiando-se nas análises feitas pelo sociólogo Nelson Mello e Souza, da Fundação Getúlio Vargas, logo na introdução do livro o seu organizador, Itamar de Freitas, afirmava que não chegamos a ser racistas segregadores, mas que também não podemos nos orgulhar da chamada democracia racial brasileira. E na época já perguntava:

Como reagiremos - por exemplo - quando os negros vencerem as dificuldades sociais e econômicas que os segregam, deixarem de ser apenas 448 universitários em 5.600.000 indivíduos? Hoje, os negros não incomodam, mas o que acontecerá quando eles tiverem - ainda que uma minoria expressiva deles - poder econômico para comprar títulos de clubes fechados, ou forçar sua entrada nos colégios mais caros, ou forçar sua admissão

\footnotetext{
${ }^{35}$ Sales Augusto dos SANTOS e Nelson Inocêncio Olokafá da SILVA, 2006.

${ }^{36} \mathrm{FRY}$ e MAGGIE, 2004. Eles escreveram também separadamente, cujo título foi "Em breve, um país dividido".

${ }^{37}$ Clóvis MOURA, 1988.
} 
nos escritórios ou postos importantes, ou morar nas zonas residenciais de "primeira classe"? Estaremos maduros, bastante para aceitá-los como irmãos em tudo, ou vamos partir para conflitos raciais?

Nota-se que o autor se posiciona como homem branco, assume que seria por iniciativa dos brancos que provavelmente haveria ataques ou conflitos raciais no Brasil do futuro. No referido livro, o tópico "Racismo no país da classe média", cujo instigante título é a "Crise racial no Brasil - ano 2000", Freitas, concordando com a análise do sociólogo Mello e Souza, conclui que poderia haver lutas raciais no Brasil do ano de 2000 , embora o país não fosse se transformar num novo Estados Unidos da América nem na África do Sul.

O que é importante ressaltar aqui é que previsões sobre a composição racial brasileira e sobre conflitos explicitamente raciais no Brasil (do futuro) existiram ao longo do império e período republicano, porém nunca se concretizaram. Aliás, o antropólogo Lívio Sansone ${ }^{39}$ sustenta que, em outros contextos sociais diversos do brasileiro, a idéia de "raça" e a etnicidade já deflagraram tumultos e até mesmo guerras, mas, no Brasil, mesmo havendo racismo contra os negros, não houve ações coletivas violentas desse tipo.

Portanto, não há antecedentes históricos que demonstrem a possibilidade de haver ampliação dos conflitos raciais no Brasil, até mesmo porque todas as previsões na área das relações raciais brasileiras feitas anteriormente por políticos e cientistas sociais não se concretizaram. ${ }^{40}$ Lamentavelmente, essas previsões ou afirmações geralmente são feitas sem nenhum suporte ou evidência histórica, nem mesmo calcadas em pesquisas. Aliás, dos autores contrários às cotas que pesquisam e estudam a questão racial citados neste artigo, raros são os que realizam pesquisas (tanto quantitativas quanto qualitativas) nas quais buscam incluir o tema das ações afirmativas, conforme se pode ver em Santos. ${ }^{41}$

Uma revisão da literatura evidencia que Maggie, ${ }^{42}$ dentre renomados cientistas sociais contrários a cotas, foi a única que buscou fundamentar alguns de seus argumentos contra o sistema de cotas por meio de pesquisas. Em publicação contendo parte dos resultados da "pesquisa sobre o impacto de políticas públicas em escolas de ensino médio do Rio de Janeiro", a autora argumenta:

a pesquisa realizada em escolas do Rio de Janeiro se insere em um projeto maior "Acompanhando as ações Afirmativas no Ensino Superior" - e mobilizou 20 estudantes de graduação e pós-graduação que empreenderam 16 estudos de caso em escolas da

\footnotetext{
38 José Itamar de FREITAS, 1969, p. 7.

39 Lívio SANSONE, 2004.

${ }^{40}$ Por exemplo, Joseph Arthur de Gobineau, o Conde de Gobineau, um dos teóricos do "racismo científico", que defendia abertamente a superioridade da raça ariana (GOBINEAU apud Georges RAEDERS, 1988), também fez previsões sobre o futuro racial do Brasil. Após viver 14 meses no Brasil, de abril de 1869 a maio de 1870, como chefe da delegação diplomática da França, Gobineau construiu uma visão sobre a população brasileira que é sabidamente pessimista. Segundo ele, "em menos de 200 anos, [...] veremos o fim da posteridade dos companheiros de Costa Cabral e dos imigrantes que o sucederam", pois o "sangue mulato" produz "rebentos que não sobrevivem" (p. 241). Gobineau considerava os brasileiros "preguiçosos", "malandros", "feios", "degradáveis", "raquíticos" e, conseqüentemente, sem futuro, porque a miscigenação extremada os conduziria a uma decadência irremediável. Com relação aos negros que habitavam o Brasil, Gobineau foi tão ou mais taxativo quanto sobre os mestiços: eram uma "depravação primitiva" (p. 121). Segundo Gobineau, "Uma população toda mulata, com sangue viciado, espírito viciado e feia de meter medo [...]. Nenhum brasileiro é de sangue puro; as combinações dos casamentos entre brancos, indígenas e negros multiplicaramse a tal ponto que os matizes da carnação são inúmeros, e tudo isso produziu, nas classes baixas e nas altas, uma degenerescência do mais triste aspecto [...] o resultado são compleições raquíticas que, se nem sempre repugnantes, são sempre desagradáveis aos olhos" (p. 90).
}

${ }^{41}$ SANTOS, 2007.

42 MAGGIE, 2005, 2005-2006, 2006. 
rede estadual e escolhidas entre as que foram classificadas com os piores indicadores a partir da avaliação do Programa Nova Escola.

Maggie ${ }^{44}$ tentando confirmar a sua tese de que o Brasil é um país altamente misturado, onde há uma classificação racial ambígua ante a mestiçagem cultural e biológica brasileira ${ }^{45}$ e, conseqüentemente, o gradiente de cor da sociedade brasileira, afirmou que a pergunta que suscitou mais dúvidas dos alunos foi sobre a identificação de cor/raça deles. Ela chegou a essa conclusão após fazer um pré-teste, por meio de questionários, com alunos das escolas públicas do Estado do Rio de Janeiro onde estava realizando a pesquisa:

Aplicamos um questionário para estudantes do primeiro ano do ensino médio. Era ainda um pré-teste. Entre as perguntas, havia uma que pedia aos estudantes que se autoclassificassem em uma das categorias do Censo Demográfico. A pergunta, igual à formulada pelo IBGE, era a seguinte: Qual é sua cor/raça: () branca () preta () parda () amarela () indígena. Essa pergunta foi a que suscitou mais dúvidas e mais reação de todo o extenso questionário. A maioria dos estudantes não queria identificar-se em nenhuma das categorias. Alguns falaram e outros escreveram à margem da resposta fechada, raça humana. Outros riam e perguntavam aos colegas, qual a minha cor? Outros ainda falaram revoltados que essa pergunta estava errada porque não existem "raças" humanas. ${ }^{46}$

Os resultados desse pré-teste aparentemente indicavam o que alguns intelectuais e pesquisadores que estudam as relações raciais brasileiras ${ }^{47}$ já afirmavam: que as cinco categorias raciais utilizadas pelo IBGE para coletar informações sobre a cor/raça são limitadas ou, ainda, de fato não fazem sentido para os brasileiros, ou seja, o pré-teste da professora Yvonne Maggie, ${ }^{48}$ ao que tudo indicava, corroborava a Pesquisa Nacional por Amostra de Domicílios " PNAD, realizada em 1976 pelo IBGE, que deixou o quesito cor/raça em aberto, isto é, espontâneo, o que permitiu verificar que naquela época os brasileiros autoclassificaram-se em 135 cores/raças. ${ }^{49}$

Por outro lado, no artigo "Racismo e anti-racismo: preconceito, discriminação e os jovens estudantes nas escolas cariocas", Maggie divulgou os primeiros resultados da pesquisa. Contudo, por paradoxal que pareça, não registra nenhuma das dificuldades comentadas em termos de classificação racial por parte dos alunos entrevistados:

Em novembro de 2005, como um desdobramento da pesquisa realizada desde 2004, fizemos um survey nas 21 escolas cariocas que eram objeto de estudos de caso intensivo, sendo 19 delas da rede estadual, uma da rede federal e uma da rede particular. [...] Fizemos a pergunta sobre "cor/raça" do censo demográfico aos entrevistados e tivemos a seguinte distribuição: $35,5 \%$ se autodeclararam brancos, $39,5 \%$ se autodeclararam pardos e $25 \%$ se autodeclararam pretos. Verificamos que estes dados revelam uma população estudantil mais escura que a população do estado do Rio de Janeiro que, segundo o censo de 2000 , compõe-se de $53,9 \%$ brancos, $33,7 \%$ de pardos, $10,9 \%$ pretos e menos de $1 \%$ amarelos e indígenas.

\footnotetext{
43 MAGGIE, 2005-2006, p. 113.

${ }^{44}$ MAGGIE, 2005, 2005-2006.

${ }^{45}$ Ver também FRY, 2005, p. 163.

${ }^{46}$ MAGGIE, 2005, p. 289. Ventura SANTOS, 2004.

${ }^{48}$ MAGGIE, 2005, 2005-2006.

49 SANTOS, 2006.

50 MAGGIE, 2006, p. 743-744.
}

47 Célia Maria Marinho de AZEVEDO, 2004; FRY, 1995-1996; MAGGIE, 2005; e Marcos Chor MAIO e Ricardo 
Considerando a ênfase que Maggie ${ }^{51}$ deu às dificuldades de os alunos se autoclassificarem de acordo com as categorias raciais utilizadas pelo IBGE no pré-teste de sua pesquisa, feito em dezembro de 2004, pensamos que ela deveria pelo menos ter comentado ou explicado por que no resultado final da pesquisa os mesmos estudantes não tiveram problemas em se autoclassificarem, visto que a totalidade $(100 \%)$ dos entrevistados se classificou como preto, branco ou pardo. Nenhum dos entrevistados se recusou a autoclassificar-se racialmente, não disse e nem insistiu que pertencia à raça humana, como fizera antes; nem mesmo deixou a resposta em branco, ou seja, não aparece nenhum resquício da recusa da maioria dos alunos manifestada anteriormente. A totalidade dos estudantes se autoclassificou em alguma das categorias raciais desse instituto.

Caso a nossa consideração seja procedente, e pensamos que ela é plausível, entendemos que os dados coletados e, conseqüentemente, as análises da pesquisa de Maggie ${ }^{52}$ podem estar comprometidos, ou seja, os seus argumentos contrários ao sistema de cotas fundamentados nessa pesquisa perdem credibilidade. Como, por exemplo, o argumento nas entrelinhas de que não se sabe quem é negro na sociedade brasileira ante a classificação racial ambígua ou, ainda, de que a maioria dos entrevistados se recusa a se autoclassificar racialmente ou não encontra na taxonomia do IBGE categorias que expressem a sua autoclassificação racial infere daí que não se pode ter um público-alvo para as políticas de ação afirmativa, especialmente para o sistema de cotas. Vale registrar que essa foi a única pesquisadora da área de ciências sociais que demonstrou ter realizado pesquisa sobre o sistema de cotas para se contrapor a ele. Contudo, como se observou, seu principal argumento contra o sistema de cotas, fundamentado na idéia de que os estudantes de ensino médio não se identificam em nenhuma das categorias raciais ou de cor utilizadas pelo IBGE, foi negado pela sua própria pesquisa.

\section{Conclusão}

Na virada do século XIX para o século XX as mulheres brasileiras iniciaram uma campanha pelo direito ao voto, ou seja, o direito eleitoral; foi o chamado movimento sufragista. ${ }^{53}$ Elas lutavam para serem respeitadas como ser humano, não serem inferiorizadas, tratadas como objeto e incapazes de pensar por si. Lutavam por manifestar opinião própria. Como os negros em suas lutas antigas e contemporâneas por igualdade racial e contra o racismo, as mulheres também sofreram fortíssimas resistências dos seus oponentes, neste caso, os homens. Portanto, enfrentaram enormes obstáculos que eram frutos do machismo.

Como acontece hoje com as propostas de ações afirmativas para negros, naquela época o debate sobre o sufrágio feminino chegou ao Congresso Nacional e à imprensa. Prevaleceu nesse debate o tom conservador no sentido de impedir que as mulheres tivessem direito ao voto. Vários argumentos foram sustentados contra o sufrágio feminino, especialmente porque se previa que ele levaria à "dissolução da família" brasileira.

Como hoje, contra os negros, os opositores de ontem, contra as mulheres, faziam previsões aterrorizantes e sem fundamentos históricos ou concretos para a sociedade brasileira caso fosse aprovado o direito de as mulheres votarem. Segundo alguns opositores ao voto feminino que participaram da Assembléia Constituinte de 1891:

Estender o voto às mulheres é uma idéia imoral e anárquica, porque, no dia em que for convertida em lei, ficará decretada a dissolução da família brasileira. ${ }^{54}$

\footnotetext{
${ }^{51}$ MAGGIE, 2005, 2005-2006.

52 MAGGIE, 2005, 2005-2006, 2006.

${ }_{53}$ Branca Moreira ALVES, 1980.

${ }^{54}$ Muniz FREIRE apud ALVES, 1980.
} 
Precisamos opor tenaz resistência, levantar um grande dique de encontro à onda devastadora que aí vem e que quer tragar, ameaçando derruir o gigantesco trabalho construtor dos nossos antepassados, na constituição da nossa nacionalidade, para $\circ$ que precisamos da mulher no seu posto de honra, onde os nossos maiores a colocaram, como sentinela e guarda do santuário da família, fundamento do organismo social. ${ }^{55}$ Embora a mulher seja capaz dos mais arrojados cometimentos, embora possa abordar a mais alta questão de transcendência matemática [...] não deve ter o direito de sufrágio, porque a sua missão é a de educar os filhos. ${ }^{56}$

As previsões feitas pelos homens contra o voto feminino não passavam de terrorismo masculino contra as mulheres. O mesmo se pode dizer contemporaneamente quando renomados cientistas sociais da área de estudos e pesquisas sobre as relações raciais brasileiras, entre outros, afirmam sem nenhum indício concreto, ou seja, apenas fazendo previsões aterrorizadoras, que a política afirmativa de sistema de cotas para negros implica "divisões perigosas", bem como levará a conflitos raciais no Brasil do futuro. Contudo, o presente nos indica outras possibilidades mais promissoras e fundamentadas em fatos concretos. Não houve a dissolução da família brasileira com a ampliação dos direitos das mulheres, pelo contrário, houve o seu fortalecimento à medida que a sociedade brasileira foi se democratizando. E não temos dúvida de que a sociedade será mais pacífica racialmente à medida que os negros e outros grupos étnico-raciais tiverem as mesmas oportunidades e os mesmos tratamentos e direitos que a população branca tem no Brasil.

As universidades ao aplicarem as ações afirmativas, destacando-se as políticas de cotas, demonstram isso, e agora com a votação do PL 73/99 na Câmara Federal avançase para a concretização por lei do caminho de geração de oportunidades para todos. As ações afirmativas devem ser aplicadas quando necessárias, sob avaliação dos representantes de órgãos públicos e de toda a sociedade, fortalecendo a relação dos movimentos sociais com os governos e também as entidades representativas dos interesses sociais por justiça e igualdade social e racial.

\section{Referências bibliográficas}

ALMEIDA, Marlise M. M. "Ações afirmativas: dinâmicas e dilemas teóricos entre a redistribuição e reconhecimento". In: II SEMINÁRIO NACIONAL e MOVIMENTOS SOCIAIS, PARTICIPAÇÃO E DEMOCRACIA, 25-27 abril 2007, Florianópolis. Anais... Florianópolis: UFSC, 25-27 abril 2007.

ALVES, Branca Moreira. Ideologia e feminismo: a luta da mulher pelo voto no Brasil. Petrópolis: Vozes, 1980.

AZEVEDO, Célia Maria Marinho de. Anti-racismo e seus paradoxos: reflexões sobre cota racial, raça e racismo. São Paulo: Annablume, 2004.

BARBOSA, Maria Inês da Silva. Racismo e saúde. 1998. Tese (Doutorado em Saúde) “ Departamento de Saúde Materno-Infantil, Faculdade de Saúde Pública, Universidade de São Paulo, São Paulo, 1998.

CARNEIRO, Sueli. "A batalha de Durban". Revista de Estudos Feministas, Florianópolis, Universidade Federal de Santa Catarina, Centro de Filosofia e Ciências Humanas e Centro de Comunicação e Expressão, v. 10, n. 1, p. 209-214, 2002. Dossiê III Conferência Mundial contra o Racismo.

CASTRO, Mary Garcia. "Políticas públicas por identidades e de ações afirmativas: acessando gênero e raça, na classe, focalizando juventudes". In: NOVAES, Regina; VANNUCHI,

${ }^{55}$ Esaú de MORAES apud ALVES, 1980.

${ }^{56}$ Barbosa LIMA apud ALVES, 1980. 
Paulo (Orgs.). Juventude e sociedade: trabalho, educação, cultura e participação. São Paulo: Fundação Perseu Abramo, 2004.

CAVALLEIRO, Eliane. Do silêncio do lar ao silêncio escolar: racismo, preconceito e discriminação na educação infantil. 1998. Dissertação (Mestrado em Educação) “ Faculdade de Educação, Universidade de São Paulo, São Paulo, 1998.

Veredas das noites sem fim: um estudo sobre o processo de socialização e a construção do pertencimento racial em gerações sucessivas de famílias negras de baixa renda. 2003. Tese (Doutorado em Educação) "Faculdade de Educação, Universidade de São Paulo, São Paulo, 2003.

CRENSHAW, Kimberle. "Documento para encontro de especialistas em Aspectos da Discriminação Racial relativos ao Gênero". Revista de Estudos Feministas, Florianópolis, Universidade Federal de Santa Catarina, Centro de Filosofia e Ciências Humanas e Centro de Comunicação e Expressão, v. 10, n. 1, p.171-188, 2002. Dossiê III Conferência Mundial contra o Racismo.

FREITAS, José ltamar de (Org.). Brasil ano 2000: o futuro sem fantasia. Rio de Janeiro: Biblioteca do Exército, 1969.

FRY, Peter. "O que a cinderela negra tem a dizer sobre a 'política racial' no Brasil". Revista USP, São Paulo, n. 28, p. 122-135, dez./fev. 1995-1996.

. "Politics, Nationality and the Meanings of Race in Brazil". Daedalus, Cambridge, EUA, v. 129, p. 83-118, 2000.

. "Política, nacionalidade e o significado de 'raça' no Brasil”. In: BETHELL, Leslie (Org.).

Brasil: fardo do passado, promessas do futuro. Rio de Janeiro: Civilização Brasileira, 2002.

. "Introduzindo o racismo". O Globo, Rio de Janeiro, 21 mar. 2003.

. A persistência da raça: ensaios antropológicos sobre o Brasil e a África austral. Rio de Janeiro: Civilização Brasileira, 2005a.

. "Ossos do ofício". Horizontes Antropológicos, Porto Alegre, ano 11 , n. 23, p. 271-272, jan./jun. 2005b.

. "Ciência social e política 'racial' no Brasil". Revista da USP, São Paulo, n. 68, p. 180-

187, dez. 2005 e jan./fev. 2006.

FRY, Peter; MAGGIE, Yvonne. "Cotas raciais: construindo um país dividido?". Econômica: Revista da Pós-Graduação em Economia da UFF, Niterói, v. 6, n. 1, p. 153-161, jun. 2004. Dossiê Ação Afirmativa.

GOMES, Joaquim B. Barbosa. Ação afirmativa e o princípio constitucional da igualdade. Rio de Janeiro: Renovar, 2001.

"Ação afirmativa: aspectos jurídicos". In: ABONG. Racismo no Brasil. São Paulo, Petrópoles: ABONG, 2002.

INSTITUTO DE PESQUISA ECONÔMICA APLICADA. Políticas sociais - acompanhamento e análise. Brasília: Ipea, 2008. n. 15.

LPP NET. Programa Políticas da Cor - PPCOR/UERJ-2008. Disponível em: www.lpp.net/olped/ acoesafirmativas/universidades_con_cotas.asp. Acesso em: set. 2008.

JACOUD, Luciana de Barros; BEGHIN, Nathalie. Desigualdades raciais no Brasil: um balanço da intervenção governamental. Brasília: Ipea, 2002.

MAGGIE, Yvonne. "Os novos bacharéis: a experiência do pré-vestibular para negros e carentes". Novos Estudos CEBRAP, São Paulo, n. 59, p. 193-202, mar. 2001.

. "Em breve, um país dividido". O Globo, Rio de Janeiro, 27 dez. 2004.

"Mário de Andrade ainda vive? O ideário modernista em questão". Revista Brasileira de Ciências Sociais, São Paulo, v. 20, n. 58, p. 5-26, jun. 2005a. 
. "Política de cotas e o vestibular da UnB ou a marca que cria sociedades divididas". Horizontes Antropológicos, Porto Alegre, ano 11 , n. 23, p. 286-291, jan./jun. 2005b.

. "Uma nova pedagogia racial?". Revista da USP, São Paulo, n. 68, dez. 2005 e jan./ fev. 2006.

"Racismo e anti-racismo: preconceito, discriminação e os jovens estudantes nas escolas cariocas". Educação e Sociedade, Campinas, v. 27, n. 96 especial, p. 739-751, out. 2006.

MAGGIE, Yvonne; FRY, Peter. "O debate que não houve: a reserva de vagas para negros nas universidades brasileiras". Enfoque: Revista Eletrônica, Rio de Janeiro, v.1, n. 1, p. 93117, 2002.

. "A reserva de vagas para negros nas universidades brasileiras". Estudos Avançados: Revista do IEA da USP, São Paulo, v. 18, n. 50, p. 67-80, 2004.

MOURA, Clóvis. Sociologia do negro brasileiro. São Paulo: Ática, 1988.

MOURA, C. A.; BARRETO, Jônatas Nunes. A Fundação Cultural Palmares na III Conferência Mundial de Combate ao Racismo, Discriminação Racial, Xenofobia e Intolerância Correlata. Brasília: Fundação Cultural Palmares, 2002.

ONU. Declaração da Conferência Mundial dos Direitos Humanos. Viena, 1993. Disponível em: http://www.pge.sp.gov.br/centrodeestudos/bibliotecavirtual/instrumentos/viena.htm. Acesso em: 6 ago. 2008.

Declaração da IV Conferência Mundial sobre a Mulher. Beijing, 1995. Disponível em: http://www.dhnet.org.br/direitos/sip/onu/doc/pequim95.htm. Acesso em: 6 ago. 2008.

ONU. Declaração e Programa de Ação da III Conferência Mundial de Combate ao Racismo, a Discriminação Racial, a Xenofobia e as Formas Conexas de Intolerância. Nova lorque, 2002.

PAIXÃO, Marcelo. Manifesto anti-racista: idéias em prol de uma utopia chamada Brasil. Rio de Janeiro: DP\&A, LPP/UERJ, 2006.

PIOVESAN, Flávia. Direitos humanos e justiça internacional: um estudo comparativo dos sistemas regionais europeu, interamericano e africano. São Paulo: Saraiva, 2007.

RAEDERS, Georges. O inimigo cordial do Brasil: o conde de Gobineau no Brasil. Rio de Janeiro: Paz e Terra, 1988.

RIBEIRO, Matilde. "Mulheres negras brasileiras, de Bertioga a Beijing". Revista de Estudos Feministas, Rio de Janeiro, v. 3, n. 2, p. 446-57, 1995. Dossiê Mulheres Negras.

. Gênero e raça no orçamento participativo em Santo André 1997-8. 1999. Dissertação (Mestrado) - Pontifícia de Universidade Católica, São Paulo, 1999.

. "O feminismo em novas rotas e visões". Revista Estudos Feministas, Florianópolis Universidade Federal de Santa Catarina, Centro de Filosofia e Ciências Humanas e Centro de Comunicação e Expressão, v. 14, n. 3, p. 801-811, 2006.

"Las mujeres negras em luta por sus derechos". Revista Nueva Sociedad, Buenos Aires, v. 218 , nov./dez. 2008.

RODRIGUES, Almira. "Reforma política e ações afirmativas". Revista Política Democrática, Brasília, DF: Fundação Astrojildo Pereira, ano III, n. 7, p. 107-111, out. 2003 e jan. 2004. SANSONE, Lívio. Negritude sem etnicidade. Salvador: Edufba; Rio de Janeiro: Pallas, 2004. MAIO, Marcos Chor; SANTOS, Ricardo Ventura. "Qual 'retrato do Brasil'?: raça, biologia, identidades e política na era da genômica". Mana, Rio de Janeiro, v. 10, n. 1, p. 61-95, abr. 2004.

SANTOS, Sales Augusto dos. Movimentos negros, educação e ação afirmativa. 2007. Tese (Doutorado em Sociologia) " Departamento de Sociologia, Universidade de Brasília, Brasília, jun. 2007. 
. "Who is black in Brazil?: a timely or a false question in brazilian race relations in era of affirmative action?". Latin American Perspectives, California, issue 149, v. 33, n. 4, p. 30-48, July 2006.

SANTOS, Sales Augusto dos; SILVA, Nelson Inocêncio Olokafá da. "Brazilian indifference to racial inequality in the labor market". Latin American Perspectives, California, issue 149, v. 33, n. 4, p. 13-29, July 2006.

TELLES, Edward Eric. Racismo à brasileira: uma nova perspectiva sociológica. Rio de Janeiro: Relume Dumará, 2003.

[Recebido em novembro de 2008

e aceito para publicação em dezembro de 2008]

\begin{abstract}
Affirmative actions: Polemics and Possibility about Racial Equality and the Role of the State

Abstract: The article analyses the importance of the role of the State for the implementation of public policies of affirmative action, especially for black students to enter public higher education. It argues that affirmative action is one of the alternatives to reduce or minimize the inequality in this field between black and white students and/or students from public schools and private schools, in particular by means of one of its techniques of implementation: the quota system. In spite of there being various arguments against the quota system, the authors concentrate on debating or counter-arguing only one: that the quota system may generate racial conflicts in Brazil.

Key Words: Public Policies; Affirmative Actions; Quota System; Higher Education; Racial Conflicts.
\end{abstract}

